\title{
Evaluation of Reverse Mortgage Programs in Korea
}

\author{
SEUNGRYUL MA* \\ Government Employees Pension Research Institute \\ Seoul, Korea \\ YONGHENG DENG** \\ National University of Singapore \\ Singapore
}

\begin{abstract}
We analyze an actuarial model of reverse mortgage programs in Korea. Our analyses provide a comparison between the reverse mortgage loans structured with constant monthly payments and those that make graduate monthly payments which are indexed to the growth rate of consumer prices. Using the total annual loan cost measure, we find that the graduate monthly payments approach is more efficient than the constant monthly payments approach. Our analyses also confirms that younger age cohorts are more sensitive to changes in their loan terms. We propose therefore that the terms of reverse mortgage programs should be structured more conservatively for the relatively younger borrower groups. The results provide useful information to reverse mortgage borrowers considering the various payment options, and pertinent guidelines for the future operation of reverse mortgage systems in Korea and elsewhere.
\end{abstract}

Keywords: Insurance premium structure, Reverse mortgage, Constant monthly payments, Graduate monthly payments, Total annual loan costs rates

\footnotetext{
* First Author. Senior Research Fellow, Government Employees Pension Research Institute. Seoul, Korea.

** Correspondent Author. Provost's Chair Professor and Director of Institute of Real Estate Studies, National University of Singapore. Singapore.
} 


\section{INTRODUCTION}

Korea is rapidly becoming an aging society. However, social security systems are largely insufficient to secure the living costs of its elderly. A government-insured reverse mortgage program was launched for the first time by the Korean government in July 2007, ${ }^{1)}$ and reverse mortgages have recently come to be recognized in Korea as an important financial vehicle by which elderly homeowners can supplement the existing social security systems. This paper evaluates the appropriateness of current Korean reverse mortgage model. It compares alternative payment schemes currently adopted in the Korean reverse mortgage program, and provides guidelines for the future operation of the reverse mortgage system.

A reverse mortgage contract allows a senior homeowner to take out a loan against the equity of his or her home. The lender makes annuity payments to the borrower as a percentage of the value of the house. In such a loan, the payment stream of the mortgage contract is reversed. The borrower does not have to make payments on the loan as long as he or she continues to live in it, but when the borrower becomes deceased and no longer occupies the house, the lender takes over the property. Reverse mortgages therefore allow equity rich but cash poor senior homeowners to convert part of their home equity into tax-free cash without having to sell their homes. It gives the seniors financial stability and independence, and also allows them the opportunity to retain control of the homes they live in.

The development of reverse mortgage programs in the United States can be traced back to the 1960's. The most popular reverse mortgage program in the U.S. currently is the Home Equity Conversion Mortgage (HECM) program, which is the only reverse mortgage insured by the U.S. federal government. The HECM was developed by the Department of Housing and Urban Development (HUD) in 1987 to accomplish three broad objects: (1) to permit the

1) Following the introduction of reverse mortgage program for the elderly homeowners, since January 1, 2011, Korean government also launched a new reverse mortgage program for the elderly farmers who are income-poor but farmland-rich for the first time in the world. However, in this analysis, we only focus on the problems related to the reverse mortgage program for the elderly homeowners. 
conversion of home equity into liquid assets to meet the special needs of elderly homeowners; (2) to encourage and to increase the participation of the primary and secondary mortgage markets in converting home equity into liquid assets; and (3) to determine the extent of demand for home equity conversion and the types of home equity conversion mortgages that best serve the needs of elderly households (Szymanoski 1994). Although numerous reverse mortgage products have been developed since then, there are three major products currently on the market, i.e., HUD's HECM, Fannie Mae's proprietary Home Keeper Mortgage, and Financial Freedom's proprietary Cash Account. Of these three major reverse mortgage products, the HECM program is currently considered the safest because it is insured by the U.S. federal government. Over 95 percent of all reverse mortgage borrowers choose the HECM product. If they choose an alternative to the HECM, a private entity provides the guarantee instead. For example, Fannie Mae, the largest nonbanking financial services company in the world, guarantees the Home Keeper Mortgages, and Financial Freedom, currently the largest private reverse mortgage lender and servicer in the U.S., guarantees the Cash Account (Ballman 2004). Mayer and Simons (1994a, b), Case and Schnare (1994), Merrill, Finkel, and Kutty (1994), and Fratantoni (1999) provide evidence of the strong demand for reverse mortgages among "house-rich, cash-poor" elderly homeowners in the U.S..

Turning to Korea, Cho, Park, and Ma (2004) estimated that the potential demand for reverse mortgage products in the country could well exceed half a million homeowners aged 60 and over. Lim and Cho (1999), Cho and Ma (2004), and Cho, Park and Ma (2004) similarly demonstrated the potential demand for reverse mortgage loans amongst elderly homeowners in the Korean housing market. The authors suggested that the government-insured reverse mortgage system play an important role in supplementing social security systems currently in place for the elderly in Korea.

Following from the HECM program that is prevalent in the U.S., reverse mortgage payments can be dispensed in several ways. The borrower may choose to receive a lump sum cash payment in advance, or in a tenure plan, payment can be made in pre-determined monthly or annual amounts to be paid as long as the owner resides in the house. Alternatively, in a term plan, an annuity can be paid for a fixed number of years (as determined by the owner) that is 
then divided into monthly cash payments. Both the tenured and term plans can be augmented by a line of credit secured against the home's value, and multiple combinations of the above options are possible. After examining the choices, the Korean government first decided to adopt a tenure plan with constant monthly payments for its reverse mortgage programs ${ }^{2}$. After a year, it launched alternative tenure plans with either graduate monthly payments pegged to inflation, or decreasing monthly payments. Among these three plans, constant and graduate monthly payments plans are the subject of the analyses in the current paper.

Because the constant monthly payment plan provides a fixed monthly amount for as long as the borrower has the house as his (her) primary residence, the real value of the cash paid to them monthly is likely to decline over time because of inflation. Considering that almost all public pension programs in Korea are designed to provide full protection against inflation, the monthly payment plan in which monthly payments are indexed to the growth rate of consumer prices ${ }^{3)}$ provides an added sense security.

For all its obvious benefits, the reverse mortgage program presents a number of risks to both the borrowers and the lenders. Under the HECM program, these risks are protected through the FHA mortgage insurance program. ${ }^{4)}$ Reverse mortgage insurance premiums consist of an up-front sum and additional monthly mortgage premiums (MIP) collected from the borrowers. For the sustainable operation of the reverse mortgage system, it is important to construct an appropriate insurance premium structure which reflects the expected claims properly. Losses due to insurance claims are expected to occur in the event that the borrower's total outstanding loan bal-

2) Policy makers in Korea posit that payments should be guaranteed over the borrower's lifetime, at least in nominal terms. Monthly payments are required by Korea reverse mortgage law in order to prevent borrowers from using up their lump sum payments without careful consideration of their future needs. It is for this reason that we focus on the method of monthly payments in this analysis.

3) In HECM program, to provide readily available cash for unexpected expenses and give borrowers a hedge against rising prices, it also allows to add a line of credit to a constant monthly advance (The American Association of Retired Person 2005).

4) If the lender fails to provide payments to the borrower, the insurer (guarantor) will take over that responsibility. After the borrower dies or move out of the home, the insurer ensures that the sale value of the home will cover the total loan amount. If the sale price is less than the accumulated payments plus interest, the insurer pays the difference to the lender (Rodda et al. 2003). 
ance exceeds the appreciated value of his (her) property at the time the loan is due and payable. However, it is well documented that the exact timing of a loan becoming due and payable is both unknown and difficult to estimate (Rodda, Herbert and Lam 2000; Rodda et al. 2003). When introducing the government-insured reverse mortgage program in Korea, it was desirable to adopt a system similar to the HECM program in the U.S. as this had been tested and successfully improved many times since its inception in 1987. Consequently, the Korean reverse mortgage model adopted the same insurance premium structure as that in the U.S. HECM program.

The existing literature, including Boehm and Ehrhardt (1992, 1994), Szymanoski (1994), Chinloy and Megbolugbe (1994), Rodda, Herbert and Lam (2000), Rodda et al. (2003), Rodda, Lam and Youn (2004) and Pu, Fan and Deng (2013), provides a thorough analysis of the risks associated with reverse mortgage loans, and presents pricing models for reverse mortgages in the U.S.. More recently, several empirical studies have been published that analyze reverse mortgage system in Korea. Yoo (2002) studied the economic effects of the reverse mortgage system, while Ma and Cho (2004) and Cho, Park and Ma (2004) analyzed the payment plans of reverse mortgages, and analyzed reverse mortgage related risks. Sung (2005) analyzed life insurer's strategies for operating the reverse mortgage loans. Cha and Jung (2008) analyzed the pricing models prevalent in reverse mortgage insurance, and $\mathrm{Ma}(2006,2008)$ suggested methods for alleviating risks embedded in the constant monthly payment program. Lew and Ma (2012) compared reverse mortgages on homes for elderly homeowners to that of farmlands reverse mortgaged by elderly farmers, focusing on their comparative cost efficiency.

The current paper builds on this literature by looking more closely at the appropriateness of current Korean reverse mortgage model. It compares the constant monthly payment program to the graduate monthly payment program, and provides guidelines for the future operation of the reverse mortgage system. The Total Annual Loan Costs (TALC) rates were first evaluated in order to calculate the actual efficiency of borrowers' costs. A sensitivity analysis was then conducted of the reverse mortgage pricing models in order to better understand the insurer's level of risk. These calculations were made based on a set of scenarios that differed in terms of interest rates and the level of appreciation in housing prices.

The remainder of the paper is organized as follows: section 2 pres- 
ents the background of Korean reverse mortgage program, section 3 presents an actuarial model of Korean reverse mortgages focusing on tenure plans, section 4 reports the results of the analysis, and the last section presents our conclusions.

\section{THE KOREAN REVERSE MORTGAGE PROGRAM}

The Korean government-insured reverse mortgage program was first launched in July 2007. To be eligible for a reverse mortgage loan, borrowers initially had to own their home, and be at least 65 years. However, in October 2008, the minimum eligible age was lowered to 60 years in order to better meet citizen needs. As outlined above, reverse mortgage programs are associated with many different types of cash advances. Table 1 compares the payment forms possible under the U.S. HECM and the Korean reverse mortgage program.

Under the HECM program, borrowers can change their payment options any time during the life of their loan, subject to a small fee. However, this is not possible after closing a loan in the Korean model. Cash advances in the Korean model take the form of tenure payments, or tenure payments along with a line of credit. In the lat-

Table 1. Comparison of payment types: U.S. HECM program vs Korean reverse mortgage (KRM)

\begin{tabular}{|c|c|c|c|}
\hline \multicolumn{2}{|c|}{ Payment type } & HECM & KRM \\
\hline Tenure advances & $\begin{array}{l}\text { constant monthly payment } \\
\text { graduate monthly payment } \\
\text { decreasing monthly payment }\end{array}$ & $\begin{array}{l}\sqrt{ } \\
- \\
-\end{array}$ & $\begin{array}{l}\sqrt{ } \\
\sqrt{ } \\
\sqrt{ }\end{array}$ \\
\hline Term advances & constant monthly payment & $\sqrt{ }$ & - \\
\hline $\begin{array}{l}\text { Tenure advances } \\
\text { Term advances co }\end{array}$ & $\begin{array}{l}\text { combined with line of credit } \\
\text { mbined with line of credit }\end{array}$ & $\begin{array}{l}\sqrt{ } \\
\sqrt{ }\end{array}$ & $\begin{array}{l}\sqrt{ } \\
-\end{array}$ \\
\hline
\end{tabular}

- Tenure advances: borrowers continue getting monthly advances until they die, sell their home, or permanently move away.

- Term advances: borrowers continue getting monthly advances for a specific period of time

- Line of credit: a personal account that the borrower controls. The borrower decides when to make a cash withdrawal from this account, and how much cash to withdraw 


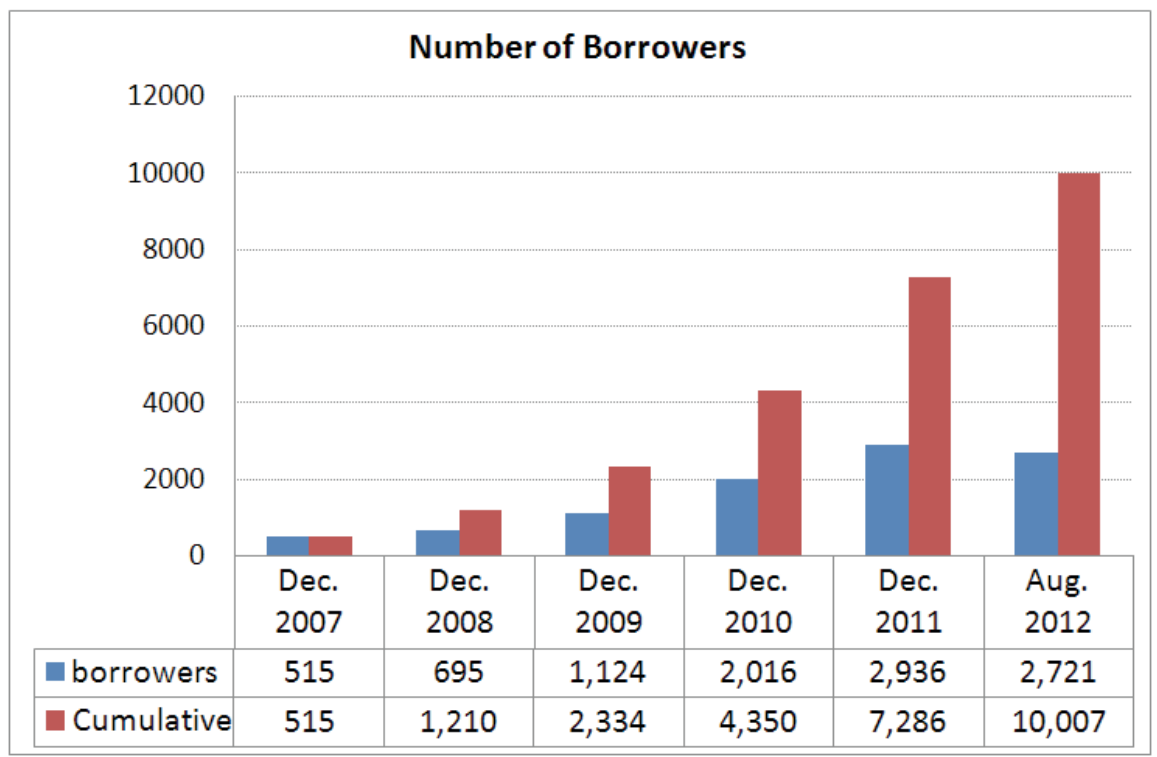

Figure1. Number of borrowers in Korean reverse mortgage

ter, lump sum withdrawals are capped at $50 \%$ of loan principal $\left(P L_{0}\right)$. In both cases, borrowers can select from constant, graduate, or decreasing payments.

The Korean Housing Finance Corporation, which is the guarantor of the Korean reverse mortgage program, has reported that the number of reverse mortgage borrowers has risen rapidly with time. Figure1 shows the annual number of reverse mortgage borrowers from the time of the mortgage's inception to Aug. 2012.

The mean value of the monthly payments was 1,030 thousand won. ${ }^{5)} 40.7 \%$ of borrowers of Korean reverse mortgages received amounts of between 500 thousand and a million won as monthly payments. Table 2 shows the distribution of borrowers in the Korean reverse mortgage program up to July 31, 2012.

5) On Oct. 7, 2012, US 1.0 dollar was equivalent to Korean 1,110.50 won. 
Table 2. Distribution of borrowers in the Korean reverse mortgage program

\begin{tabular}{l|c}
\hline \hline Age cohorts & $11.2 \%$ \\
$60-64$ & $21.2 \%$ \\
$65-69$ & $28.6 \%$ \\
$70-74$ & $22.6 \%$ \\
$75-79$ & $16.4 \%$ \\
80 and above & \\
(The average borrowers' age is 73) & $9.5 \%$ \\
\hline House Value & $30.6 \%$ \\
Below 100 million won & $24.5 \%$ \\
100-200 million won & $15.1 \%$ \\
200-300 million won & $8.6 \%$ \\
300-400 million won & $11.7 \%$ \\
$400-500$ million won & \\
500 million won and over & \\
(The average House Value is 278 million won) & $61.3 \%$ \\
\hline Payment Types & $38.7 \%$ \\
Tenure advances & \\
Tenure advances combined with a line of credit & $76.5 \%$ \\
\hline Payment Options & $0.9 \%$ \\
Constant & $22.6 \%$ \\
Graduate & \\
Decreasing & \\
\hline
\end{tabular}

\section{ACTUARIAL MODEL OF KOREAN REVERSE MORTGAGE}

\section{Korean Government Sponsored Reverse Mortgage Model}

We compute the breakeven level of monthly payments in the Korean reverse mortgage model using the trial and error method under the condition that the present value of the mortgage insurance premium (PVMIP) is equal to the expected loss (PVEL) following the traditional principle of insurance pricing (Ma 2008).

$$
\begin{aligned}
\text { PVMIP } & =U p_{0}+\sum_{t=1}^{T(x)} \frac{\operatorname{mip}_{t} \times{ }_{t} p_{x}}{(1+i)^{t-1}} \\
& =\sum_{t=1}^{T(x)}\left\{\frac{\max \left[\left(O L B_{t}-H_{t}\right), 0\right] \times{ }_{t} d_{x}^{*}}{(1+i)^{t}}\right\}=P V E L
\end{aligned}
$$




$$
\begin{aligned}
& \operatorname{mip}_{t}=\left(O L B_{t-1}+p m t_{t}\right) \times m \\
& O L B_{t}=\left(O L B_{t-1}+p m t_{t}\right)(1+m)(1+i), \\
& H_{t}=H_{0} \times(1+g)^{t}
\end{aligned}
$$

where, $U p_{0}$ is the upfront mortgage insurance premium, $T(x)$ is the remainder of the payment period until loan termination, mip $_{t}$ is the monthly mortgage insurance premium, $O L B_{t}$ is the outstanding loan balance, $p m t_{t}$ is the monthly payments, $H_{t}$ is the expected house value, $g$ is the growth rate of housing price, ${ }_{t} p_{x}$ is the probability that a borrower at age $x$ will survive at $x+t,{ }_{t} d_{x}{ }^{*}$ is the probability that a loan will be terminated between the age $x+t$ and $x+t+1$, i is the expected interest rate, and $m$ is the rate of insurance premium.

In equation (1), the expected interest rate $i$ stands for expected value of the actual interest rate of the loan during its period. To simplify things for the seniors borrowing money under the reverse mortgage program, the Korean government adopted a fixed interest rate. This fixed rate is used to calculate the outstanding loan balance $\left(O L B_{t}\right)$ in each period, and is used also in the calculation of the PVMIP and PVEL. Borrowers receive the payments in the form of an annuity until the loan is terminated.

This expected interest rate is different from the actual interest rate $\left(r_{t}\right)$ that is charged at the initiation of the reverse mortgage loan. Lenders charge adjustable interest rates on reverse mortgage loans and the rate is determined by adding the predetermined margin of $1.1 \%$ to the $\mathrm{CD}$ (certificate of deposit) rate at time $t$. In this case, the $\mathrm{CD}$ rate becomes the reference interest rate $\left(r_{t}=C D_{t}+1.1 \%\right)$. Because the $\mathrm{CD}$ rates fluctuate, the insurer of the reverse mortgage program could face either a net loss or gain.

Maximum Constant Monthly Payment. Under the constant monthly payment scheme, the annuity payment $p m t_{c}$ is computed under the condition that PVMIP is equal to PVEL.

$$
p m t_{c}=\frac{N P L_{0}}{\sum_{t=0}^{T(x)-1}\left[\frac{1}{(1+i)(1+m)}\right]^{t}}
$$

where $p_{m} t_{c}=$ the annuity payment (constant monthly payment)

$N P L_{0}=$ the net value of loan principal $\left(N P L_{0}=P L_{0}-U p_{0}\right)$ 


$$
P L_{0}=H_{0} \times \operatorname{LTV}\left(L T V=\text { Loan to Value } \text { ratio }^{6}\right)
$$

Maximum Graduate Monthly Payments. The graduate monthly payments scheme alleviates the risk of a decrease in purchasing power over time as payments are indexed to the mean value of the growth rate of consumer prices. We can calculate the minimum amount $\left(p m t_{0}\right)$ of the graduate monthly payments under the condition that PVMIP is equal to PVEL.

$$
p m t_{o}=\frac{N P L_{0}}{\sum_{t=0}^{T(x)-1}\left[\frac{1+c}{(1+i)(1+m)}\right]^{t}}
$$

where $p m t_{0}=$ the base amount of graduate monthly payment $c=$ the mean value of the growth rate of consumer prices

\section{Total Annual Loan Costs (TALC) Rates}

The TALC rate is the annual average rate that includes all the costs involved in a reverse mortgage, without considering the survival probabilities of the loan. The advantage of the TALC method is that it presents the total cost of the loan using a single rate at the specific period $(t=n)$ when the borrowers reach the age of 100 (Scholen 1996).

Constant Monthly Payment. Under the constant monthly payments scheme, we can calculate the TALC rates (TALCR) at the period $t=n$ in equation (4) using a trial and error method.

$$
\operatorname{Min}\left(O L B_{n}, H_{n}\right)=p m t_{c} \sum_{t=0}^{n}(1+T A L C R)^{n-t}
$$

Graduate Monthly Payment. In the case of graduate monthly payments, we can also calculate TALC rates at period $t=n$ in equation (5) using the trial and error method.

6) LTV is the ratio of present value of the mortgage benefits to the borrower's initial house value. In other words, it is the ratio of a single lump sum premium in immediate annuity to the house value. 


$$
\operatorname{Min}\left(O L B_{n}, H_{n}\right)=p m t_{0} \sum_{t=0}^{n}[(1+c)(1+T A L C R)]^{n-t}
$$

\section{The Value of Key Factors}

Loan Survivals and Termination Probabilities. Because historical data on reverse mortgage termination rates (the probability that the loan will become due and payable) were simply not available, the U.S. HUD used a number of untested assumptions in determining probable termination rates, including that the prepayment rate would be 0.3 times the mortality rate of the youngest borrower in the family. ${ }^{7}$ In the Korean reverse mortgage model, the loan termination probability was generated under the assumption that the prepayment rate would be 0.2 times the 2005 mortality rate for females. This adjustment was made after considering Koreans demographic data. This data was updated in 2012, and the 2010 mortality rate was instead adopted in the actuarial model (Lew and Ma, 2012). The relationship between the monthly loan survival probabilities $\left.{ }_{(t} p_{x}\right)$ and the termination probabilities $\left.{ }_{t} d_{x}^{*}\right)$ is demonstrated below.

$$
{ }_{t} d_{x}^{*}={ }_{t} p_{x} \times d_{x+t}={ }_{t} p_{x}-{ }_{t+1} p_{x}
$$

where $d_{x+t}=$ modified mortality rate after considering the prepayment rate at age $x+t$ $d_{x+t}=q_{x+t} \times 1.2$, $q_{x+t}=2010$ mortality rate for females at age $x+t$

Figure 2 shows the loan survival probabilities $\left({ }_{t} p_{x}\right)$ and Loan termination probabilities $\left({ }_{t} d_{x}^{*}\right)$ that were applied in the actuarial model of Korean reverse mortgages.

The Growth Rate of Housing Prices, and Expected Interest Rates. In the Korean reverse mortgage model, the growth rate of housing prices was assumed to be $3.5 \%$ per annum, based on the mean housing

7) HECM loans terminate when the borrower leaves her home permanently, simply chooses to pay off the loan, or when she dies. Because actual termination related data was not yet available when the premiums were originally set, an assumption was made that terminations would occur at 1.3 times the rate of mortality (Rodda, Lam and Youn 2004). 

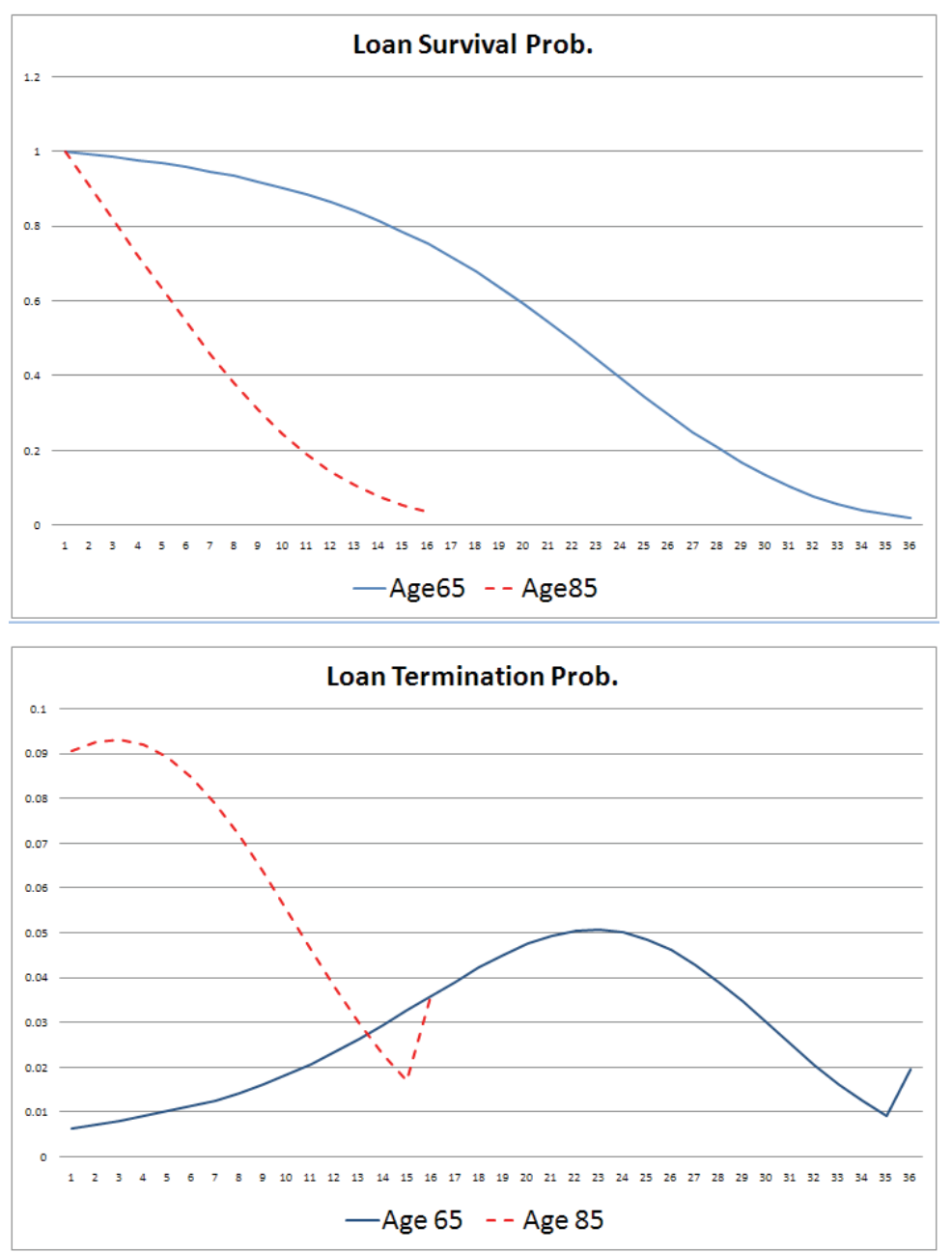

Figure 2. Loan survival and termination probabilities (at age 65 and age 85)

price growth rate in the years between 1986 and 2006. Because the mean value of the 10-year government bond rates was $5.12 \%$ between June 2002 and May 2007, the expected interest rate was assumed to be $7.12 \%$ per annum in this period after adding a lender's margin of $2 \%$.

Because of subsequent changes in the economic environment, the housing price growth rate was adjusted in Feb 2012 to 3.3\%, and the expected interest rate was also adjusted to $6.33 \%$ in the 
actuarial model (Lew and Ma 2012).

Upfront Cost. In the Korean reverse mortgage model, the up-front insurance premium is $2 \%$ of a house's value. The monthly mortgage insurance premium (MIP) is calculated based on an annual rate of $0.5 \%$ of the loan's outstanding balance. In this analysis, we assume that the up-front cost involves only an up-front premium of $2 \%$ of the home's value. ${ }^{8)}$ When determining the level of the monthly payment, we first evaluate the present values of the expected claim losses and the expected insurance premiums under the predetermined insurance premium structure. Next, if there is a discord in present values of the PVEL and PVMIP, we modify the level of the monthly payments using a trial and error method.

\section{THE RESULTS}

\section{The LTV Ratios and Monthly Payments}

As indicated earlier, we focus in this paper on two payment methods possible under the tenure plan. One is the constant monthly payments method, and the other is the graduate monthly payment method which is indexed to the growth rate of consumer prices. The LTV ratios and monthly payment levels which satisfy the conditions of the actuarial equivalence principle (PVMIP=PVEL) are as follows. We assume in our analysis that the up-front cost is $2 \%$ of housing value. Table 3 shows the maximum values of the LTV ratios and the

8) In the HECM, after loan closing, every borrowers is required to pay 2 percent of the maximum claim amount (adjusted property value) as an up-front (initial) insurance premium, as well as a monthly MIP according to the annual rate of $0.5 \%$ of the loan's outstanding balance (Rodda, Herbert and Lam 2000; Rodda et al. 2003). The itemized costs of a HECM loan includes an origination fee, thirdparty closing costs, an up-front mortgage insurance premium, a monthly MIP, a servicing fee, and interest (AARP 2005). In 1999, the typical HECM borrowers paid $\$ 1,800$ in origination fees, $\$ 1,500$ in closing costs, $\$ 2,100$ in up-front insurance premiums or a total of $\$ 5,400$ for initiating a HECM (Rodda, Lam and Youn 2004). In this analysis, we assume that the up-front cost is composed only of the up-front insurance premium ( $2 \%$ of housing values) because the other costs are relatively small in the Korean reverse mortgage model. The upfront cost creates a large hurdle that has essentially blocked the refinancing of reverse mortgages. Therefore, prepayment rates in reverse mortgage loans can be controlled by the up-front costs (Szymanoski 1994; Rodda, Lam and Youn 2004). 
Table 3. Maximum value of LTV ratios and monthly payments (unit: 1,000 won)

\begin{tabular}{l|c|c|c|c|c|c|c}
\hline \hline \multicolumn{2}{l|}{} & 60 & 65 & 70 & 75 & 80 & 85 \\
\hline \multirow{6}{*}{ Cons } & $P L_{0}$ & 125,452 & 145,005 & 167,869 & 194,248 & 223,226 & 251,146 \\
& PVMIP & 16,111 & 14,806 & 13,327 & 11,768 & 10,302 & 9,072 \\
& LTV & $41.82 \%$ & $48.33 \%$ & $55.95 \%$ & $64.75 \%$ & $74.41 \%$ & $83.72 \%$ \\
& $p m t_{c}$ & 720 & 861 & 1,042 & 1,284 & 1,616 & 2,091 \\
\hline \multirow{2}{*}{ Grad } & $P L_{0}$ & 132,587 & 153,697 & 178,092 & 205,701 & 235,089 & 261,886 \\
& PVMIP & 14,879 & 13,782 & 12,528 & 11,192 & 9,922 & 8,844 \\
& LTV & $44.19 \%$ & $51.23 \%$ & $59.36 \%$ & $68.56 \%$ & $78.36 \%$ & $87.29 \%$ \\
& pmt0 & 508 & 628 & 788 & 1,008 & 1,319 & 1,778 \\
\hline
\end{tabular}

Note: $1 . P L_{0}=300$ million won * LTV ratio

2. The mean value of the growth rate of the consumer price index was assumed to be $3 \%$ per annum

3. Cons: constantly monthly payment program, Grad: graduate monthly payment program

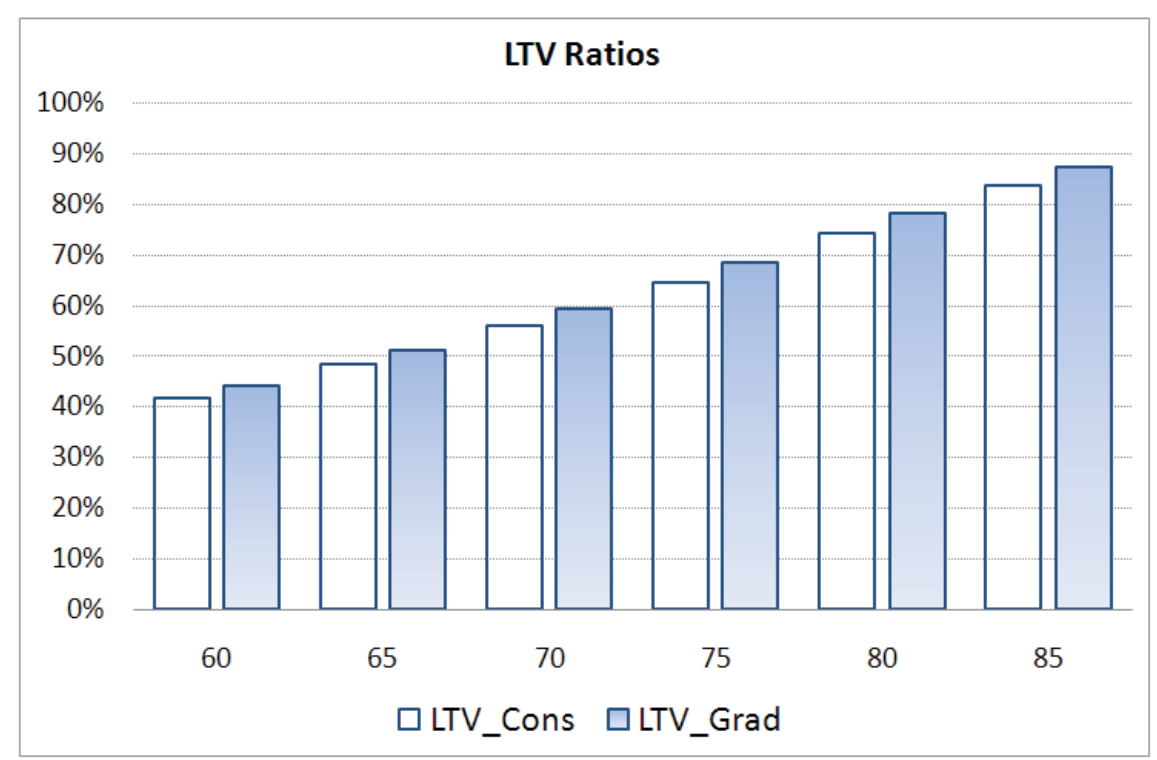

Figure 3. Comparison of LTV ratios

monthly payments when the price of all the borrowers' homes is assumed to be 300 million won.

As Table 3 demonstrates, because there is a proportional relationship between the level of LTV and a borrower's age, a relatively older 


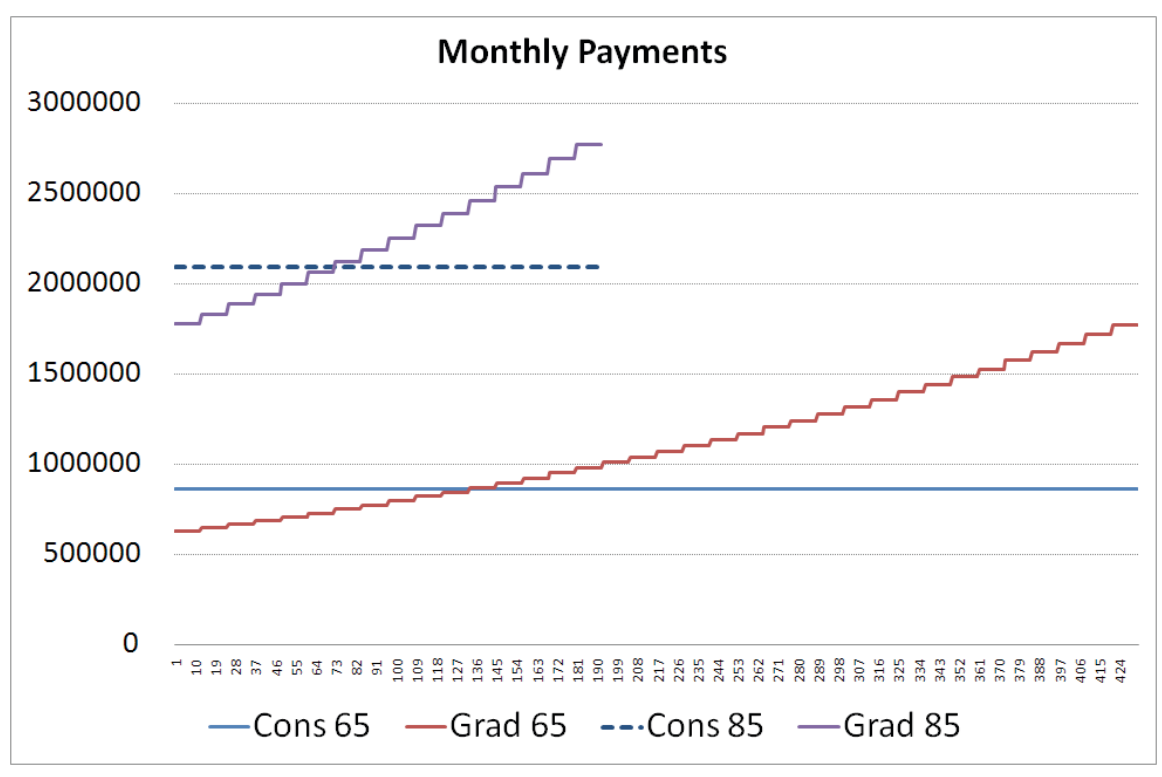

Figure 4. Trend of monthly payments in Korean reverse mortgages

group of borrowers could receive larger monthly payments than a relatively younger group of borrowers. Figure 3 illustrates the LTV ratios of borrowers on both the constant and graduate monthly payment programs according to the borrower's age. We can confirm that the LTV ratios of the constant monthly payment program are relatively smaller than that of the graduate monthly payment program for individuals in the same age group. The results indicate on average that the borrowers who select the graduate option gain greater profits from the reverse mortgage program.

Figure 4 shows the trend of monthly payments in Korean reverse mortgage programs. In the graduate monthly payment program, the level of monthly payment increases by $3 \%$ each year as we can see from Grad 65 (the case of a borrower aged 65) and Grad 85 (the case of a borrower whose age is 85) in Figure 4.

\section{Evaluating Total Annual Loan Costs (TALC) Rates}

In the graduate monthly payment program, the level of LTV is bigger than in the constant monthly payment program, but the value of the PVMIP is smaller. Thus, we expect the value of the 
Table 4. Total annual loan costs

\begin{tabular}{c|c|c|c|c|c|c}
\hline \hline \multirow{2}{*}{$\mathrm{n}$} & \multicolumn{2}{|c|}{ Age 65 } & \multicolumn{2}{c|}{ Age 75} & \multicolumn{2}{c}{ Age 85 } \\
\cline { 2 - 7 } & Cons & Grad & Cons & Grad & Cons & Grad \\
\hline 24 & $31.64 \%$ & $38.47 \%$ & $24.32 \%$ & $28.00 \%$ & $18.03 \%$ & $19.50 \%$ \\
72 & $10.23 \%$ & $10.65 \%$ & $9.16 \%$ & $9.16 \%$ & $8.29 \%$ & $8.04 \%$ \\
120 & $8.20 \%$ & $7.85 \%$ & $7.76 \%$ & $7.28 \%$ & $7.41 \%$ & $6.85 \%$ \\
192 & $7.44 \%$ & $6.65 \%$ & $7.14 \%$ & $6.41 \%$ & $1.69 \%$ & $0.80 \%$ \\
312 & $5.94 \%$ & $4.96 \%$ & $3.37 \%$ & $2.09 \%$ & & \\
432 & $4.31 \%$ & $2.78 \%$ & & & & \\
\hline
\end{tabular}

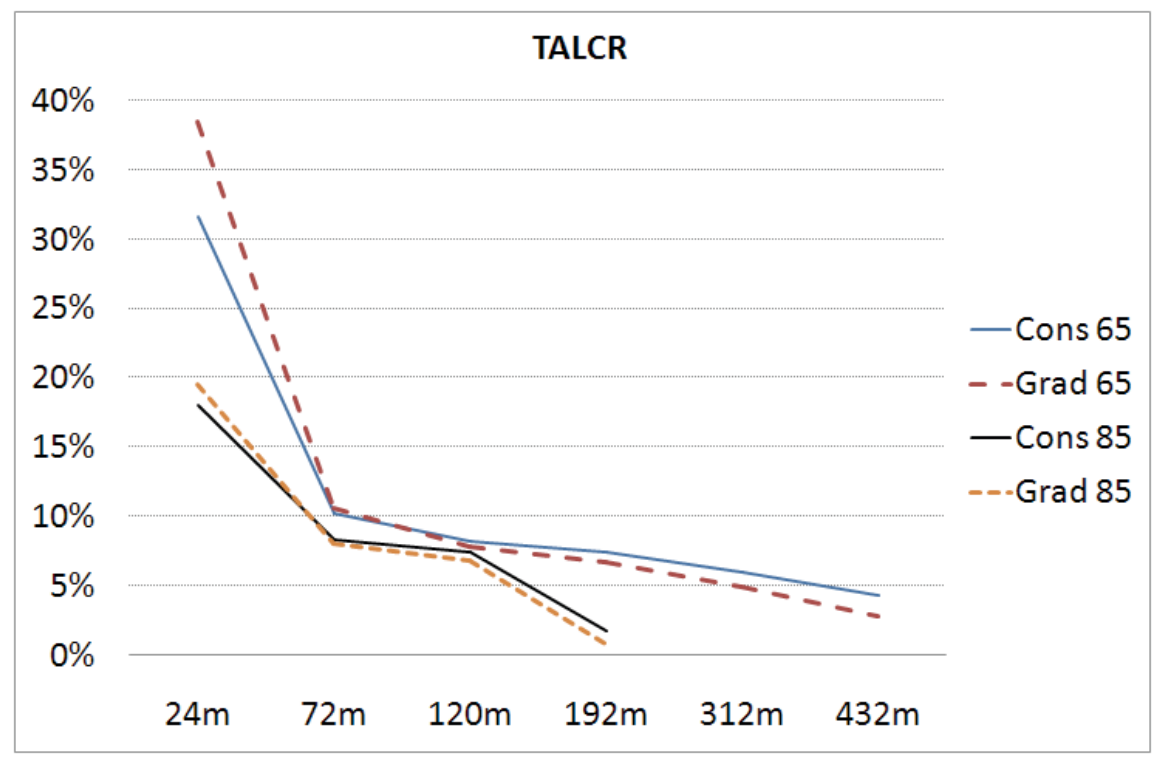

Figure 5. TALC rates (age 65 and 85)

TALC to also be smaller in the graduate monthly payment program compared to the constant monthly payment program. We evaluate the values of the TALC rates on both the payment programs. Table 4 reports the rates evaluated at various times $(t=n)$ according to the borrowers' age.

Under the HECM program, there is a overall cap that comes into effect if the borrower's rising loan balance grows equal to the value of the home. This limit is called the "non-recourse" limit (AARP 2005 ) and is set at $93 \%$ of the home's value, leaving $7 \%$ for the costs 
of selling the home (Scholen 1996). In the Korean reverse mortgage program, the non-recourse limit was assumed to be $91 \%$ of the home's value after taking into account particularities of the Korean housing market. Figure 5 shows the TALC rates by comparing two monthly payment plans in the case of borrowers aged 65 and 85, respectively.

TALC rates decline over time because the ratio of up-front costs to total debt shrinks over time, and also because the borrowers' total outstanding loan balances at time $t=n$ is limited by the value of their homes. In Figure 5, approximately after $n=72$ and at age 65 and 85, the TALC rates in the method of constant monthly payments (Cons) become bigger than that of the graduate monthly payments (Grad). From the borrowers' perspective, Figure 5 suggests that the method of graduate monthly payments (Grad) is on average more cost efficient than the constant monthly payments (Cons) method because of changes in the borrowers' life expectancy. A borrower is expected to live an additional 252 months at age 65, and an additional 84 months at age 85. Thus, borrowers who believe that their lifetime is likely to exceed that of the general population may benefit greatly by selecting the method of graduate monthly payments.

In the real world, however, as we reported in Table 2, only $0.9 \%$ of Korean reverse mortgage borrowers select the graduate monthly payments option. According to a recent study by Kim and $\mathrm{Ma}$ (2011), the demand for reverse mortgages in Korea is fuelled mainly by elderly individuals whose public pension is insufficient to meet their living expenses. Such borrowers perhaps select the constant monthly or decreasing monthly payment plan because such plans give them a relatively large amount of money upfront. However, this indicates also that reverse mortgage borrowers in Korea do not recognize the economic benefit of the graduate monthly payment scheme. ${ }^{9}$ We hope this analysis provides pertinent information for future borrowers faced with the task of selecting their payment options.

9) We examined the TALC rates in the method of decreasing monthly payments (Dec) and found the rates in Dec to be bigger than Cons after $n=72$ at age 65 and 85 . 
Table 5. Sensitivity test results (constant monthly payments) (unit: 1,000 won)

\begin{tabular}{|c|c|c|c|c|c|c|c|}
\hline Age & Assumption & Combination & $P L_{0}$ & $p m t_{c}$ & PVEL & PVMIP & $\begin{array}{l}\text { PVEL/ } \\
\text { PVMIP }\end{array}$ \\
\hline \multirow[t]{9}{*}{65} & \multirow[t]{3}{*}{ Optimistic } & $g=4.3 \%, i=5.5 \%$ & \multirow[t]{9}{*}{145,005} & \multirow[t]{9}{*}{861} & 309 & 15,240 & 0.020 \\
\hline & & $g=4.3 \%, i=6.33 \%$ & & & 3,177 & 14,806 & 0.215 \\
\hline & & $g=4.3 \%, i=7.0 \%$ & & & 7,230 & 14,483 & 0.499 \\
\hline & \multirow[t]{3}{*}{ stable } & $g=3.3 \%, i=5.5 \%$ & & & 8,315 & 15,240 & 0.546 \\
\hline & & $g=3.3 \%, i=6.33 \%$ & & & 14,806 & 14,806 & 1.000 \\
\hline & & $g=3.3 \%, i=7.0 \%$ & & & 19,984 & 14,483 & 1.380 \\
\hline & \multirow[t]{3}{*}{ pessimistic } & $g=2.3 \%, i=5.5 \%$ & & & 23,218 & 15,240 & 1.524 \\
\hline & & $g=2.3 \%, i=6.33 \%$ & & & 29,412 & 14,806 & 1.986 \\
\hline & & $g=2.3 \%, i=7.0 \%$ & & & 33,704 & 14,483 & 2.327 \\
\hline Age & Assumption & Combination & $P L_{0}$ & $p m t_{c}$ & PVEL & PVMIP & $\begin{array}{l}\text { PVEL/ } \\
\text { PVMIP }\end{array}$ \\
\hline \multirow[t]{9}{*}{85} & \multirow[t]{3}{*}{ Optimistic } & $g=4.3 \%, i=5.5 \%$ & \multirow[t]{9}{*}{251,146} & \multirow[t]{9}{*}{2,091} & 3,504 & 9,145 & 0.383 \\
\hline & & $g=4.3 \%, i=6.33 \%$ & & & 5,040 & 9,072 & 0.556 \\
\hline & & $g=4.3 \%, i=7.0 \%$ & & & 6,325 & 9,015 & 0.702 \\
\hline & \multirow[t]{3}{*}{ stable } & $g=3.3 \%, i=5.5 \%$ & & & 7,377 & 9,145 & 0.807 \\
\hline & & $g=3.3 \%, i=6.33 \%$ & & & 9,072 & 9,072 & 1.000 \\
\hline & & $g=3.3 \%, i=7.0 \%$ & & & 10,415 & 9,015 & 1.155 \\
\hline & \multirow[t]{3}{*}{ pessimistic } & $g=2.3 \%, i=5.5 \%$ & & & 11,885 & 9,145 & 1.300 \\
\hline & & $g=2.3 \%, i=6.33 \%$ & & & 13,554 & 9,072 & 1.494 \\
\hline & & $g=2.3 \%, i=7.0 \%$ & & & 14,839 & 9,015 & 1.646 \\
\hline
\end{tabular}

\section{Sensitivity Analysis}

In this section, we examine the changes in insurer's risk that result from the fluctuation in both house price appreciation rates and in interest rates. The actuarial model for Korean reverse mortgages currently assumes a $3.3 \%$ per annum appreciation rate in house prices, and an expected interest rate of $6.33 \%$ per annum. The simulated results from actuarial model are generally quite sensitive to the assumptions on house price appreciation and interest rates (Rodda, Herbert and Lam 2000). For sensitivity testing, 
Table 6. Sensitivity test results (graduate monthly payments) (unit: 1,000 won)

\begin{tabular}{|c|c|c|c|c|c|c|c|}
\hline Age & Assumption & Combination & $P L_{0}$ & $p m t_{0}$ & PVEL & PVMIP & $\begin{array}{l}\text { PVEL/ } \\
\text { PVMIP }\end{array}$ \\
\hline \multirow[t]{9}{*}{65} & \multirow[t]{3}{*}{ Optimistic } & $g=4.3 \%, i=5.5 \%$ & \multirow[t]{9}{*}{153,697} & \multirow[t]{9}{*}{628} & 790 & 14,220 & 0.056 \\
\hline & & $g=4.3 \%, i=6.33 \%$ & & & 3,423 & 13,782 & 0.248 \\
\hline & & $g=4.3 \%, i=7.0 \%$ & & & 6,566 & 13,459 & 0.488 \\
\hline & \multirow[t]{3}{*}{ stable } & $g=3.3 \%, i=5.5 \%$ & & & 8,828 & 14,220 & 0.621 \\
\hline & & $g=3.3 \%, i=6.33 \%$ & & & 13,782 & 13,782 & 1.000 \\
\hline & & $g=3.3 \%, i=7.0 \%$ & & & 17,696 & 13,459 & 1.315 \\
\hline & \multirow[t]{3}{*}{ pessimistic } & $g=2.3 \%, i=5.5 \%$ & & & 22,352 & 14,220 & 1.572 \\
\hline & & $g=2.3 \%, i=6.33 \%$ & & & 26,888 & 13,782 & 1.951 \\
\hline & & $g=2.3 \%, i=7.0 \%$ & & & 30,031 & 13,459 & 2.231 \\
\hline Age & Assumption & Combination & $P L_{0}$ & $p m t_{0}$ & PVEL & PVMIP & $\begin{array}{l}\text { PVEL/ } \\
\text { PVMIP }\end{array}$ \\
\hline \multirow[t]{9}{*}{85} & \multirow[t]{3}{*}{ Optimistic } & $g=4.3 \%, i=5.5 \%$ & \multirow[t]{9}{*}{261,886} & \multirow[t]{9}{*}{1,778} & 3,806 & 8,916 & 0.427 \\
\hline & & $g=4.3 \%, i=6.33 \%$ & & & 5,115 & 8,844 & 0.578 \\
\hline & & $g=4.3 \%, i=7.0 \%$ & & & 6,199 & 8,787 & 0.705 \\
\hline & \multirow[t]{3}{*}{ stable } & $g=3.3 \%, i=5.5 \%$ & & & 7,440 & 8,916 & 0.834 \\
\hline & & $g=3.3 \%, i=6.33 \%$ & & & 8,844 & 8,844 & 1.000 \\
\hline & & $g=3.3 \%, i=7.0 \%$ & & & 9,954 & 8,787 & 1.133 \\
\hline & \multirow[t]{3}{*}{ pessimistic } & $g=2.3 \%, i=5.5 \%$ & & & 11,617 & 8,916 & 1.303 \\
\hline & & $g=2.3 \%, i=6.33 \%$ & & & 12,969 & 8,844 & 1.466 \\
\hline & & $g=2.3 \%, i=7.0 \%$ & & & 14,016 & 8,787 & 1.595 \\
\hline
\end{tabular}

we assume three possible annual house price appreciation rates $(g=$ $2.3 \%, 3.3 \%, 4.3 \%)$, and three possible interest rates $(i=5.5 \%, 6.33 \%$, $7.0 \%)$. We test the rates using data for borrowers aged 65 and 85 . Tables 5 and 6 report the results of the sensitivity analyses of the actuarial model by looking at the house price appreciation rates and expected interest rates for borrowers aged 65 (i.e. relatively younger borrowers group) and 85 (i.e. relatively older borrowers group).

In Tables 5 and 6, and in Figure 6, we see that the variability in the ratios of PVEL to PVMIP is distinctly higher for the relatively younger age group (e.g. age 65) than for the relatively older age 


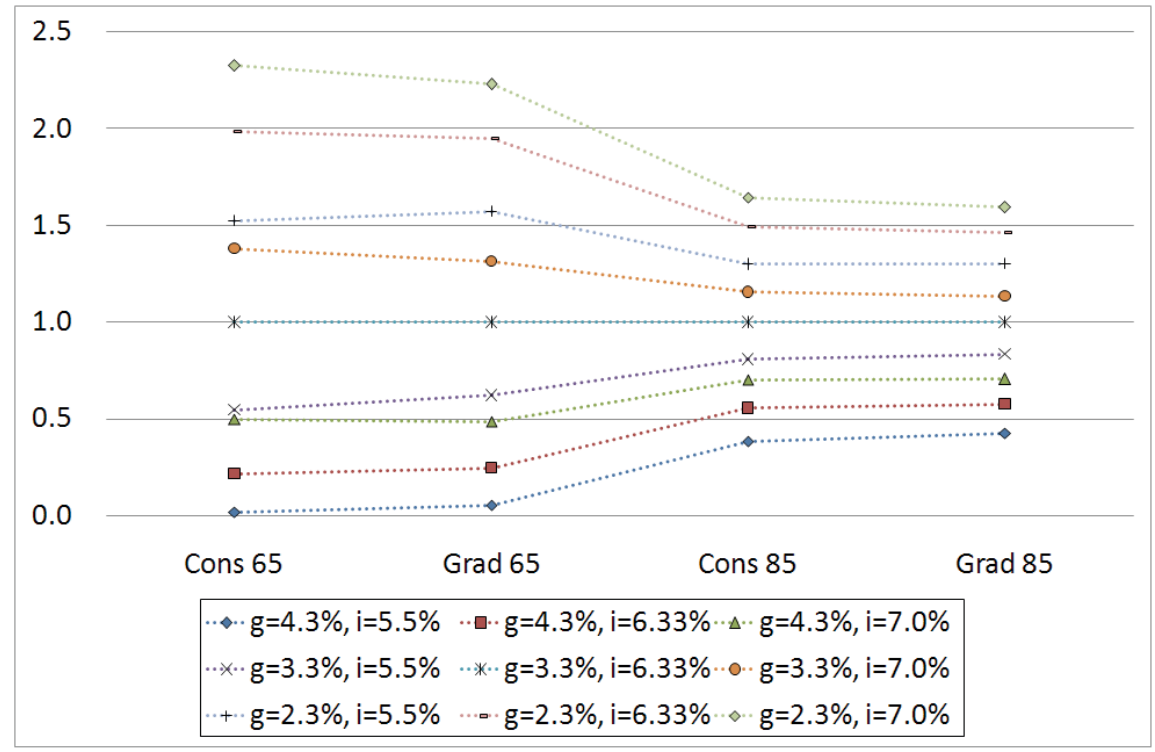

Figure 6. Sensitivity comparisons (ratios of PVEL to PVMIP)

group (e.g. age 85) due to changes in the loan terms. These results suggest that the magnitudes of sensitivity for the older borrowers is higher than that of younger ones (e.g. age 65) who are more sensitive to the shock of changes in house price and interest rates than the relatively older age group (e.g. age 85).

The results in Table 5 and Table 6 indicate that the PVEL values will be altered both by fluctuations in the housing price growth rates, and in the expected interest rates. However, the PVMIP value will only be changed by fluctuations in the expected interest rate. Considering the results of the sensitivity test (Tables 5 and 6), it becomes clear that the actuarial model adopted for Korea's single insurance premium structure should be set up more conservatively for the relatively younger borrower group than for the older borrower group. This is because the variability in the PVEL to PVMIP ratio is more sensitive to potential shocks in the growth rate of housing price and to expected interest rates in the relatively younger group.

Under the single insurance premium structure adopted here, we can consider setting the expected interest rate $(i)$ in accordance with the borrowers' age. In order to construct a simple model which can be easily understood by elderly home owners, we choose to 
fix the expected interest rate in the model. Also for the sake of simplicity, the present values of expected insurance premiums and expected claim losses are assumed to stay constant regardless of the loan duration. However, considering the cash flow risks from each contract, it is prudent to expect that interest rates will in fact differ markedly according to loan duration. Following from this, the expected interest rate for the relatively younger age group should be higher than that of older borrowers. Consequently, monthly payments calculated using the more realistic interest rates would be lower than that calculated using the current Korean reverse mortgage model for the relatively younger age group.

The current paper analyzed Korean reverse mortgage programs using a deterministic model of housing prices and interest rates. However, the interest rate associated with a borrower's outstanding loan balance will inevitably fluctuate after the loan is closed, as will the reference interest rate (that is the yield on a CD with a 91 day maturity). As such, housing values can also be expected to move stochastically. Following from this, if the reverse mortgage lender continuously pays a constant amount to borrowers every month according to the equations and assumptions in this analysis, the reverse mortgage insurer could suffer serious market risks in the long term. Therefore, it is important to follow this study with an evaluation of a reverse mortgage insurer's risk after considering the stochastic processes of housing prices and interest rates, as well as after considering the longevity risk.

\section{CONCLUSION}

Insurance claim losses are expected to occur in the event that a borrower's total outstanding loan balance exceeds the market value of the property at the time the loan is due and payable. A reasonable insurance premium structure can prevent reverse mortgage lenders to be overly exposed to the market risks. We analyzed the Korean reverse mortgage system focusing primarily on the constant monthly payments method and the graduate monthly payments method where monthly payments are indexed to the growth rate of consumer prices. We evaluated the values of the TALC rates associated with these mortgages, and found that from a borrower's perspective, the graduate monthly payments approach is more 
efficient than the constant monthly payments approach. Finally, we conducted a sensitivity analysis and found that the younger age group (e.g. age 65) is more sensitive to the shocks in future house price appreciation rates and interest rates compared to the relatively older age group (e.g. age 85). Therefore, the actuarial model in the Korean reverse mortgage system should be set more conservatively for younger than older borrowers. The results of this study offer valuable insight into the actuarial model of the reverse mortgage system and information provided can better inform the selection of payment options by reverse mortgage borrowers. Most importantly perhaps, the findings of the present study provide useful guidelines for the future operation of reverse mortgage systems in Korea.

\section{REFERENCES}

AARP (The American Association of Retired Person) (2005), Home Made Money: A Consumer's Guide to Reverse Mortgages.

Ballman, T. E. (2004), The Reverse Mortgage Hand Book: A Consumer's Guide for Senior Homeowners. Jawbone Publishing Co.

Boehm, T. P. and M. C. Ehrhardt (1992), "Are Reverse Mortgages Suitable Bank Investments?” Real Estate Review Fall, 40-45.

(1994), "Reverse Mortgages and Interest Rate Risk, "Journal of the American Real Estate and Urban Economics Association, 22(2), 387-408.

Case, B. and A. B. Schnare (1994), "Preliminary Evaluation of the HECM Reverse Mortgage Program," Journal of the American Real Estate and Urban Economics Association, 22(2), 301-346.

Cha, I. K. and H. J. Jung (2008), "A Study on the Pricing Model in Reverse Mortgage Insurance Using Option Theory," The Journal of Risk Management, 19(1), 3-49.

Chinloy, P. and I. F. Megbolugbe (1994), "Reverse Mortgages: Contracting and Crossover Risk. Journal of the American Real Estate and Urban Economics Association, 22(2), 367-386.

Cho, D. H. and S. R. Ma (2004), "Economic feasibility of reverse mortgage annuity for the elderly housing welfare," Korea Housing Studies Review, 12(1), 175-199.

Cho, D. H., C. K. Park, and S. R. Ma (2004), A Study on Introduction of Reverse Mortgage System, Korea Financial Supervisory Service.

Fratantoni, M. C. (1999), "Reverse Mortgage Choices: A Theoretical and Empirical Analysis of the Borrowing Decisions of Elderly Homeowners." Journal of Housing Research, 10(2), 189-208.

Kim, J. J. and S. R. Ma (2011), "A Study on the Determinants of the De- 
mand for Reverse Mortgage in Korea," Journal of Korea Real Estate Academy, 46, 207-225.

Lew, K. O. and S. R. Ma (2012), "A Study on Evaluating Total Loan Cost Rate of the Reverse Mortgage Products," Housing Studies Review, 20(3), 77-102.

Lim, K. S. and D. H. Cho (1997), "A Feasibility of the Reverse Mortgage System for the Residential Stabilization of the Elderly. Journal of the Korea Gerontological Society, 19(1), 1-13.

Ma, S. R. (2006), "Estimating VaR of Reverse Mortgages and a Plan for Risk Alleviation," The Journal of Risk Management, 17(2), 103-133. (2008), "Securitization of Insurer's Risk in Reverse Mortgages," Korean Insurance Journal, 80, 63-90.

and D. H. Cho (2004), "Payment Plans of Reverse Mortgage System in the Korean Housing Market," The First International Solar Cities Congress.

Mayer, C. J. and K. V. Simons (1994a), "Reverse Mortgages and the Liquidity of Housing Wealth," Journal of the American Real Estate and Urban Economics Association, 22, 235-255.

(1994b), "A New Look at Reverse Mortgages: Potential Market and Institutional Constraints," New England Economic Review, March/ April, 15-26.

Merrill, S. R., M. Finkel, and N. K. Kutty (1994), "Potential Beneficiaries from Reverse Mortgage Products for Elderly Homeowners: An Analysis of American Housing Survey Data," Journal of the American Real Estate and Urban Economics Association, 22(2), 257-299.

Pu, Ming, Gang-Zhi Fan, and Yongheng Deng (2013), "Breakeven Determination of Loan Limits for Reverse Mortgages under Information Asymmetry," Forthcoming in Journal of Real Estate Finance and Economics, DOI 10.1007/s11146-013-9415-2.

Rodda, D. T., C. Herbert, and H. K. Lam (2000), Evaluation Report of FHA's Home Equity Conversion Mortgage Insurance Demonstration: Final Report, The U.S. Department of Housing and Urban Development.

Rodda, D. T., A. Youn, H. Ly, C. N. Rodger, and C. Thompson (2003), Refinancing Premium, National Loan Limit, and Long-Term Care Premium Waiver for FHA's HECM Program: Final Report. The U.S. Department of Housing and Urban Development.

Rodda, D. T., K. Lam, and A. Youn (2004), "Stochastic Modeling of Federal Housing Administration Home Equity Conversion Mortgages with Lowcost Refinancing," Real Estate Economics, 32(4), 589-617.

Scholen, K. (1996), Your New Retirement Nest Egg: A Consumer Guide to the New Reverse Mortgages $2^{\text {nd }}$ Edition. NCHEC Press.

Sung, J. H. (2005), "Life Insurer's Strategy for Operating the Reverse 
Mortgage Loan System: In View of Estimating the Potential Collateral Loss. Korean Insurance Association Conference 2004 Winter.

Szymanoski, Jr., E. J. (1994), "Risk and the Home Equity Conversion Mortgage," Journal of the American Real Estate and Urban Economics Association, 22(2), 347-366.

Yoo, S. J. (2002), "A Study on the Economic Effects of the Reverse Mortgage System on the National Economy. Journal of the Korean Planners Association, 37(2), 147-158.

Received October 17, 2012 Revision Received March 18, 2013 Accepted May 04, 2013 